\title{
Mucosa of the Lip
}

National Cancer Institute

\section{Source}

National Cancer Institute. Mucosa of the Lip. NCI Thesaurus. Code C12226.

The lining of the fleshy folds surrounding the mouth. It is comprised of the epithelium, basement membrane, lamina propria mucosae, and lamina muscularis mucosae. 